\title{
Simple to complex tools for sustainable water resource management
}

\author{
S. Ashby, D. Richards \& R. Wallace \\ U.S. Army Engineer Research and Development Center, USA
}

\begin{abstract}
The U.S. Army Corps of Engineers has developed a system of tools to improve environmental forecasting and decision-making in comprehensive water resources management. Currently available tools include geospatial assessment techniques, habitat and index-based models, single- and multi-dimensional numerical models, and ecological models based on concepts of bioenergetics, individual-based response, and trophic structure. Applications of these models for sustainable water resource management provide opportunities to assess and predict landscape changes, owing to activities such as urbanization, ecosystem restoration, water resource project operations, etc. at various temporal and spatial scales. Since resources (e.g., data, time, expertise, funding, etc) are often limited, a tiered or hierarchical approach to water resources management is recommended. For example, geospatial technologies can be used to develop land cover and land use data layers for applications in habitat-based models or numerical models for watershed runoff predictions. Index-based models can be used in conjunction with stakeholder-developed performance criteria to forecast potential adaptive management trajectories for sustained and multi-purpose use of water resources. Another level of water resource assessment combines predictions of land use changes and subsequent changes in material loadings with potential biological response in aquatic systems using multi-dimensional models. This suite of tools has been developed within a framework to "customize" comprehensive tool selection in the decision-making process, thus ultimately allowing user communities to maintain databases, conduct alternative analyses, and transfer information in a user-friendly format. Selected case study applications are presented to demonstrate this concept.
\end{abstract}

Keywords: watersheds, geospatial, modeling, habitat, visualization. 


\section{Introduction}

Water resource management is complicated by changing land use practices in the watershed, alterations of natural streamflows associated with withdrawals and impoundments, and impacts on biological communities in rivers and floodplains. Challenges associated with developing and managing water resources such as population growth, economic development, and greater appreciation of the value of water as identified by the World Bank (http://web.worldbank.org) [1] are applicable worldwide. Compounded by changes in water availability associated with climate variability, degraded water quality, changes in infrastructure and impacts of invasive species, water resource managers are in need of a suite of tools for water supply analysis that can be applied to diverse assessments for sustainable management and defendable decision making.

A variety of tools can be used to evaluate or simulate the influences on the services provided by a water resource system. These tools vary in levels of data required and complexity to use. Examples include geospatial tools, soil erosion models, empirically-based nutrient loading models, and physics-based or mechanistic models. Similarly, ecological models also vary in levels of data required and indication of biological response to changes in physical and chemical drivers.

Field observations (e.g., expert opinion) are often used to classify watershed features within a Geographical Information System (GIS). GIS tools can then be used to conduct analysis such as summary of land use types, proximity to similar habitat types, and summary of sources that contribute to material loading during runoff events. More quantitative methods can then be employed using empirical relationships and physics-based numerical modeling. Impacts to biological habitats can then be predicted and scenario analysis can be conducted. This approach is demonstrated with a summary of selected applications.

\section{Geospatial assessments of watersheds with index-based modeling}

Watershed studies often involve the use of aerial and satellite images, topographic maps, and other sources of geospatial information to characterize land use, distribution patterns, and significant features such as habitat patchiness and anthropogenic influences. Mapping these features and incorporating indexbased assessments of salient features into a GIS framework can facilitate assessments and inform decision makers when multiple management activities are under consideration.

One example of such an application is represented by a series of studies conducted in watersheds in California, USA [1]. Initial efforts involve the delineation of sub-basins in the watershed and development of a GIS layer that includes attributes such as vegetation cover, hydrologic features, and, for urban watersheds, transportation networks and impervious cover. The next step is to characterize these attributes. Often an index-based method (e.g., using a scalar system) is employed. For example, for hydrologic attributes in an urban area a 
range of indices can be developed that allows ranking of various stream types based on alterations or connectivity to the floodplain. A natural stream would receive the highest value (e.g., 5 on a scale of 1-5) and a completely channelized stream (as often happens for storm water management) would receive a 1 . Similar characterization can be conducted for other watershed attributes and then GIS layers are developed for depicting spatial distribution of attribute quality.

Figure 1 provides a representation of the watershed assessment and prioritization process. In figure 1A, aerial photography is combined with topographic information to delineate the watershed of interest and begin land cover classification. Figure 1B, depicts a representative GIS map where attribute indices have been used to rank sub-basins. Indicator scores can be depicted as bar charts (Figure 1C) as another visualization of attribute ranking. Areas of interest (e.g., high priority or critical areas) can then be mapped with respect to potential for restoration and proximity to urban features that may play an important role in the decision-making process (Figure 1D). This type of assessment also allows alternative analyses to consider cumulative ecological features such as connectivity, corridors, and patchiness.

A
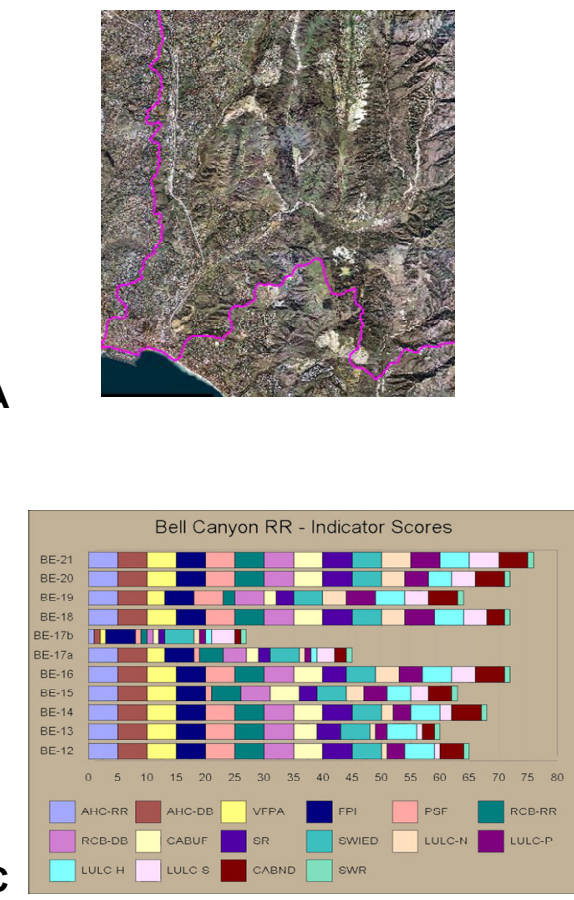

B

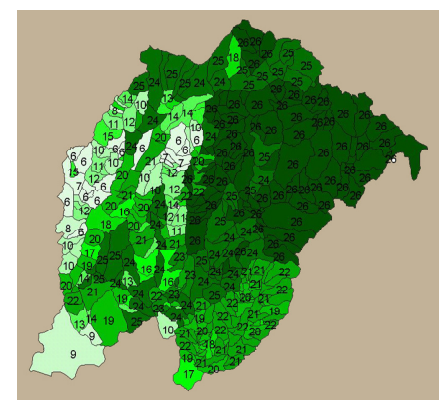

D

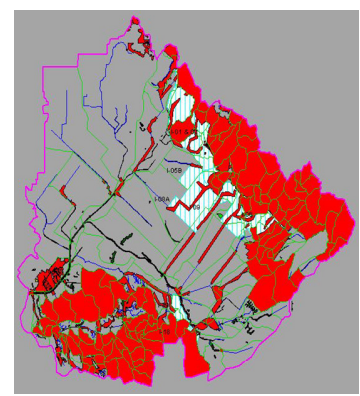

Figure 1: Example of geospatial assessment and index-based approach for prioritization of habitat restoration in an urban watershed. 


\section{Hydrodynamic modeling of watersheds}

In general, hydrodynamic modeling of watersheds involves the use of simple runoff models such as the Universal Soil Loss Equation and its variations, lumped-parameter models, and physic-based distributed models. Several frameworks for constructing watershed models now exist that provide a variety of tools. Two major examples include the Better Assessment Science Integrating point \& Non-point Sources (BASINS) developed for the U.S. Environmental Protection Agency http://www.epa.gov/waterscience/BASINS/ and the Watershed Modeling System (WMS) developed by the U.S Army Corps of Engineers http://chl.erdc.usace.army.mil/wms. These frameworks provide a comprehensive graphical modeling environment for all phases of watershed hydrology and hydraulics. Many of these models are applicable for both agricultural watersheds and urban applications.

One of the more complex watershed models that includes interactions with surface and ground water is the Gridded Surface Subsurface Hydrologic Analysis (GSSHA) model. Because the model is grid-based, it offers detailed spatial resolution capabilities versus lumped parameter models that rely on larger hydrological response units. The GSSHA model was applied to a small watershed in west-central Wisconsin, USA (French Creek) to simulate water quality response in runoff during the spring, summer, and fall seasons in an agricultural watershed [2]. The study was conducted in the watershed of the Eau Galle Reservoir. Land use in the 5 hectare watershed is primarily corn production. The geology of the area is a glacial till overlying a karst bedrock of limestone and dolomite. Subsurface flow development is also common.

Precipitation, flow, suspended solids, and selected forms of nutrients were measured throughout the watershed (Figure 2A). Soil and overland flow nutrient dynamics were developed from field and laboratory studies and subsequent algorithms were incorporated into GSSHA [3, 4]. Observed and simulated fluxes of sediments, nitrate, and dissolved inorganic phosphorus were mostly in agreement using the GSSHA model (Figures 2B, 2C, and 2D, respectively). With the exception of a late autumn runoff event (e.g., Julian day 280), observed and simulated values were in agreement. Management scenarios to reduce soil and soluble nutrient runoff can be tested on a grid (i.e., essentially field by field) basis from the calibrated model.

\section{Integration of habitat assessment with hydrologic modeling}

One of the major challenges in combining habitat assessments with hydrologic modeling is different time-scale requirements for near and long term assessments. Several approaches can be used that allow the use of short-term simulations with multi-dimensional hydrodynamic models that produce habitat information such as velocities and direction that provide habitat information for specific biological activities (e.g. migrating fish). Another approach uses more generalized hydrologic information such as inundation regimes (i.e., depth, 
A
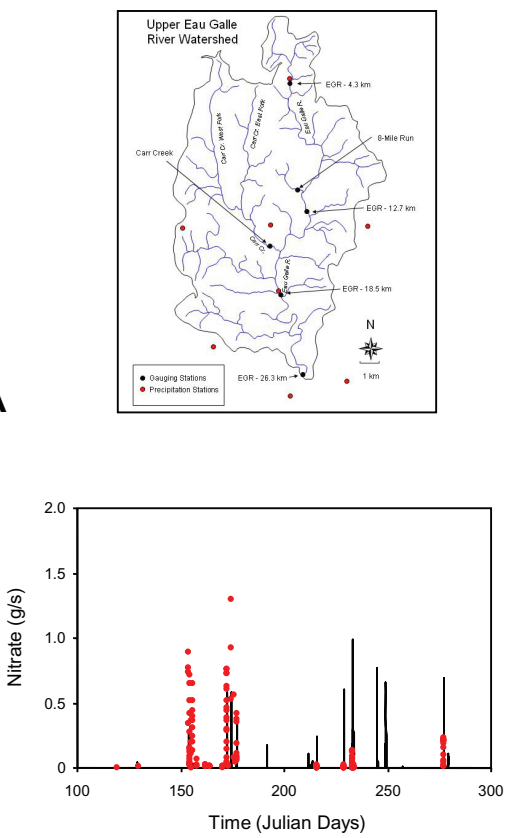

C

Figure 2: $\quad$ Site map, and material fluxes for GSSHA simulations at Eau Galle Reservoir, WI, USA (French Creek subbasin).

timing, rise and fall) and flooded land cover type with biological requirements such as spawning and rearing for fish, and seed germination and seedling success for plants.

Hydrologic models with habitat requirements (or suitability indexes) are often applied in river floodplains and ecosystem restoration projects. The hydrology is often based on historical records, availability of water associated with operations of dams, and simulations for desired inundation patterns. Using habitat suitability curves derived in a consensus approach by experts, restoration alternatives were evaluated for the Middle Rio Grande River in New Mexico, USA [5]. Scientists provided potential flow regimes and utilized geospatial analytical techniques to overlay flow on land use types to identify potential restoration sites.

The Habitat Evaluation and Assessment Tool (HEAT) was used to conduct habitat assessments for potential riparian and floodplain restoration alternatives (Figure 3A). Initially, similar to the geospatial assessment previously described, GIS coverage of habitat types were developed but the analysis also included hydrologic information such as timing, duration, and frequency of floodplain inundation. The hydrograph features are significant to riparian and floodplain species such as cottonwood trees and fish. Consequently, habitat types and 
A

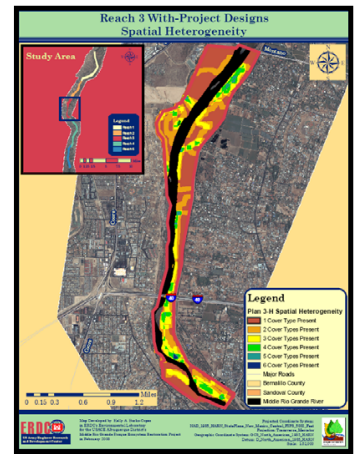

B

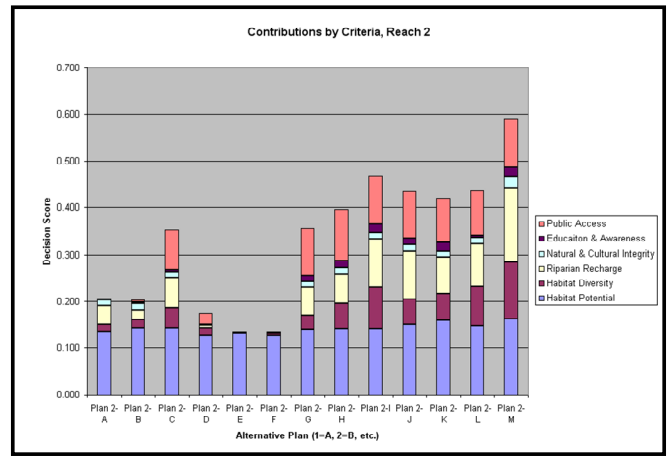

Figure 3: Geospatial depiction of potential riparian habitat types (A) and graphic representation of an example alternatives analysis (B).

quality are dependent upon possible hydrographs, especially in managed rivers. Ranking criteria can then be applied for scenario analysis and inform decisionmakers on various alternatives (Figure 3B).

\section{Visualization of assessment outputs}

Watershed assessments entail many complex and detailed interactions that have a wide variety of significance to a diverse group of stakeholders (those with vested interest in watershed management activities). Often complex and intricate studies are conducted and a large amount of information is compiled. This forms the basis for comparing water resource management alternatives. Given the diversity of the stakeholders and alternatives, effective communication of potential outcomes is essential.

Typical means of conveying assessment outputs to stakeholders include public forums with pictures, charts, and graphs. While useful in providing summary information from the assessments, graphic representations can confuse individuals and become a focus for points of contention. Detailed evaluation of assessment outputs is necessary for informed decision-making but effective representation of potential results for various management alternatives is critical for moving the process forward.

Recent innovations in graphical representations, visualization of assessment outcomes (e.g., animation of model simulations), and incorporation into platforms that provide local imagery now provide a method for effectively depicting multiple potential scenarios in a realistic manner using animation. One approach employs commercially available technology (e.g., Google Earth) and integration of GIS coverage and model simulations as described above.

Figure 4 depicts a screen capture of an animation of model output from a storm event in the watershed of the Eau Galle Reservoir, WI, USA. Air moisture information was used to indicate precipitation intensity (Figure 4A). Runoff 
A

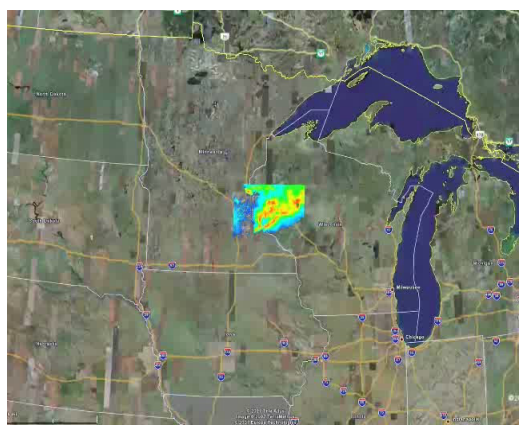

B

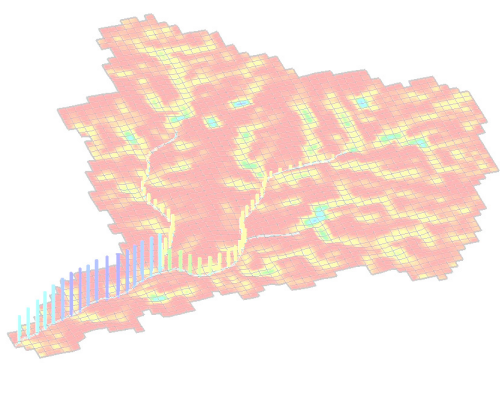

Figure 4: Image from an animation of air moisture (A) and runoff simulation (B) using GoogleEarth for time series visualization.

predictions using GSSHA were used to produce changes in water surface elevation during the event (Figure 4B). GoogleEarth technology was used to provide local imagery and visualization techniques (including some animation software) to show time series data in a geospatial context.

\section{Summary and conclusions}

A wide range of tools are available for sustainable water resource management. Often the use of these tools is limited by availability of data and expertise for applications. However, the intent of the assessment should drive the selection of tools so that identified issues can be appropriately addressed. For example, if urban expansion is projected in a basin, impacts on water resources could include increased demands on the supply, changes in runoff hydrology and water quality, and degradation of habitat. Often a geospatial approach is sufficient if decisions can be made from maps. If more quantitative methods are needed, field observations and expert opinions to characterize potential impacts on water resources can be included in the assessment. More rigorous numerical modeling can be utilized where required (e.g., regulatory applications). Finally, effective communication of the outcome from the tools used is imperative in water resource management to ensure that stakeholders fully understand the implications of various alternative management activities.

\section{Acknowledgements}

This work was conducted as an activity of the System-Wide Water Resources Program, U.S. Army Corps of Engineers (USACE). Permission was granted by the Chief of Engineers to publish this information. 


\section{References}

[1] Smith, R. D., C. V. Klimas, and B. A. Kleiss. (2005). "A Watershed Assessment Tool for Evaluating Ecological Condition, Proposed Impacts, and Restoration Potential at Multiple Scales." SWWRP Technical Notes Collection, ERDC TN-SWWRP-05-3, U.S. Army Engineer Research and Development Center, Vicksburg, MS.

[2] Downer, C. W. (2008). "Demonstration of GSSHA Hydrology and Sediment at Eau Galle Watershed near Spring Valley, Wisconsin." ERDC TN-SWRRP-08-2. Vicksburg, MS: U.S. Army Engineer Research and Development Center.

[3] James, W. and Johnson, B. (2007). "Algorithm Considerations for Evaluating Phosphorus Transport and Environmental Management Strategies Using a Grid-Based Spatial Watershed Model." ERDC TNSWRRP-07-11. Vicksburg, MS: U.S. Army Engineer Research and Development Center.

[4] Johnson, B. and Gerald, T. (2006). "Development of a Distributed Nutrient Sub-Model (NSM Version 1.0) for watershed - Kinetic Process Description.” ERDC TR-SWWRP-06, Vicksburg, MS: U.S. Army Engineer Research and Development Center.

[5] Burks-Copes, K. A., Webb, A.C, Henderson, J.E., and Payne, B.S. 2008. Middle Rio Grande Bosque Ecosystem Restoration Feasibility Study Habitat Assessment Using Habitat Evaluation Procedures (HEP), Ecosystem Services, and Spatial Heterogeneity: Analyses, Results And Documentation, Draft Report. U. S. Army Engineer Research and Development Center, Environmental Laboratory, Vicksburg, MS. 